\title{
EDUCAÇÃO MATEMÁTICA INCLUSIVA: MUSICALIDADE, NEUROCIÊNCIA COGNITIVA E MEDIAÇÃO DOCENTE ${ }^{1}$
}

\author{
Herica Cambraia Gomes, Pontifícia Universidade Católica de São Paulo (PUC - SP), \\ Instituto Federal do Rio de Janeiro (IFRJ), \\ herica.cambraia.ifrj@gmail.com
}

Ana Lucia Manrique, Pontifícia Universidade Católica de São Paulo (PUC - SP), analuciamanrique@gmail.com

\begin{abstract}
RESUMO
Em busca de novas estratégias para a efetivação da Educação Matemática Inclusiva, onde todos usufruam do seu direito de aprender, objetiva-se identificar, por meio da perspectiva docente, impactos da Musicalidade nos processos neurocognitivos da aprendizagem matemática nos anos iniciais do ensino fundamental. A ancoragem teórica da neurociência cognitiva considera: a epigenética, as janelas de oportunidades, a plasticidade cerebral e a modularidade. Neste estudo, com ênfase nas Funções Executivas (Atenção Voluntária e Memória Operacional), no Modelo explicativo do processamento numérico Código Triplo, e os critérios da mediação docente são indicados pela Teoria da Modificabilidade Cognitiva Estrutural. A organização da Musicalidade pauta-se nas relações entre elementos da corporeidade, cognição musical, percepção e expressão rítmica e sonora, constituídas em processo nato, típico de humanos. As etapas denominadas: a) Escuta Sonora Sensível; b) Biorritmo Natural e Sugerido; e c) Embalo e Relaxamento, configuram a pesquisa de abordagem qualitativa como processo não linear, mas dialético. Neste artigo apresentou-se um experimento com uma professora do segundo ano do ensino fundamental que em sua turma havia um aluno com TDAH. Ela criou uma atividade a partir do quadro de elementos neurocognitivos, que contemplam as funções executivas e os códigos do processamento numérico. A contribuição concretiza-se na proposta de formação docente visando a potencialização do ensino da matemática inclusiva, via estimulação de habilidades de atenção voluntária, memória operacional e controle inibitório para a construção do conhecimento do sistema de numeração decimal e realização do cálculo mental.
\end{abstract}

PALAVRAS-CHAVE: Educação Matemática Inclusiva; Musicalidade; Neurociência Cognitiva; Mediação Docente.

\section{INTRODUÇÃO}

A Na busca de novas estratégias para o ensino da matemática, a partir da observação do comportamento de alunos da educação básica referente ao impacto positivo da musicalidade na criatividade e motivação dos processos de aprendizagem, organizou-se

${ }^{1} \mathrm{O}$ presente trabalho contou com apoio financeiro da Coordenação de Aperfeiçoamento de Pessoal de Nível Superior (Capes), fundação do Ministério da Educação (MEC). 
etapas fundamentadas na perspectiva da neurociência cognitiva da matemática, como área interdisciplinar de conhecimentos, visando possibilitar a inclusão de todos os alunos.

Considerando a demanda sociológica presente no século XXI, em observância de: gráficos referentes à retenção e evasão de alunos; adaptações curriculares de alunos com deficiência, em processos de inclusão; e da constituição da formação de professores, apresenta-se como desafio a compreensão de habilidades neurocognitivas típicas do pensamento matemático, suas conexões e estratégias didáticas para estimulação com vistas à potencialização e modificabilidade cognitiva. Neste artigo pretende-se relatar impactos da musicalidade no ensino na educação matemática inclusiva, indicados por uma professora do segundo ano do ensino fundamental, com vinte alunos sendo um portador TDAH. Portanto, trata-se de um recorte do experimento, que é parte da pesquisa realizada por professores da educação básica referente ao sistema de numeração decimal e cálculo mental por meio da Musicalidade.

\section{Referencial Teórico}

A neurociência cognitiva é um campo interdisciplinar que investiga potenciais neurais dos processos mentais e contribui com o ensino abordando a perspectiva do pensamento matemático, suas habilidades e competências a partir das possibilidades de estratégias visando a estimulação.

As identificações, constituintes desta competência, abrangem um campo científico muito mais amplo do que discutir, apenas, sobre conteúdos programáticos, ou sobre "o que aprender da matemática", diz respeito aos sistemas matemáticos de representação utilizados como ferramentas para conceituar e representar o mundo; ao estabelecimento de relações entre elementos da realidade e suas representações; da capacidade de operar sobre situações problemas; da organização das relações numéricas e espaciais; recorrendo às convenções da cultura; enfim, à adoção de mecanismos neurocognitivos potencializadores, necessários à aprendizagem.

Alguns animais e seres humanos compartilham habilidades básicas de perceber e comparar quantidades não simbólicas. Em humanos essas habilidades são o alicerce para a construção de futuras representações numéricas simbólicas e por isso demanda de instruções 
ao longo do desenvolvimento, que compreendido como um sistema cerebral pode ser descrito pela fusão integral e relacional entre habilidades do processamento numérico específico e habilidades cognitivas amplas, denominadas de funções executivas (LURIA, 1981; LEZAK, 1982), entendidas como um conjunto de habilidades e capacidades cognitivas que nos permitem executar ações necessárias para atingir um objetivo. Que inferem: planejamento, controle inibitório, tomada de decisões, flexibilidade cognitiva, memória de trabalho, atenção, categorização, fluência e criatividade, responsáveis pela aprendizagem intelectual, que fundamentam a elaboração de novas estratégias e novas aprendizagens representados na Figura 01 (MALLOY-DINIZ et.al., 2010).

Figura 01 - Habilidades constituintes das Funções Executivas

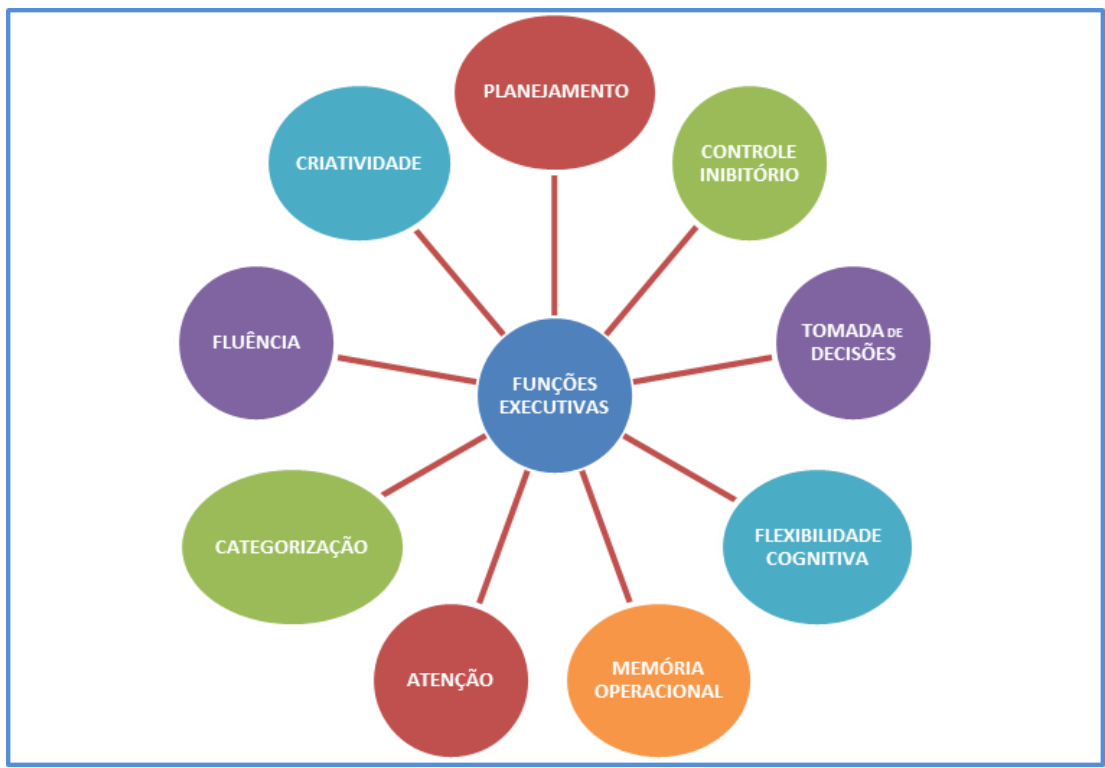

Fonte: Malloy-Diniz, Paula, Loschiavo-Alvares (2010)

Quanto ao modelo explicativo do sistema de numeração proposto pela literatura adotou-se o denominado Modelo Código Triplo (DEHAENE; COHEN, 1995) que postula a existência de três diferentes códigos para a representação cognitiva dos números: um código auditivo verbal, um código arábico visual e um código de magnitude analógica representados na Figura 02.

Figura 02 - Rota Numérica: Modelo Código Triplo 


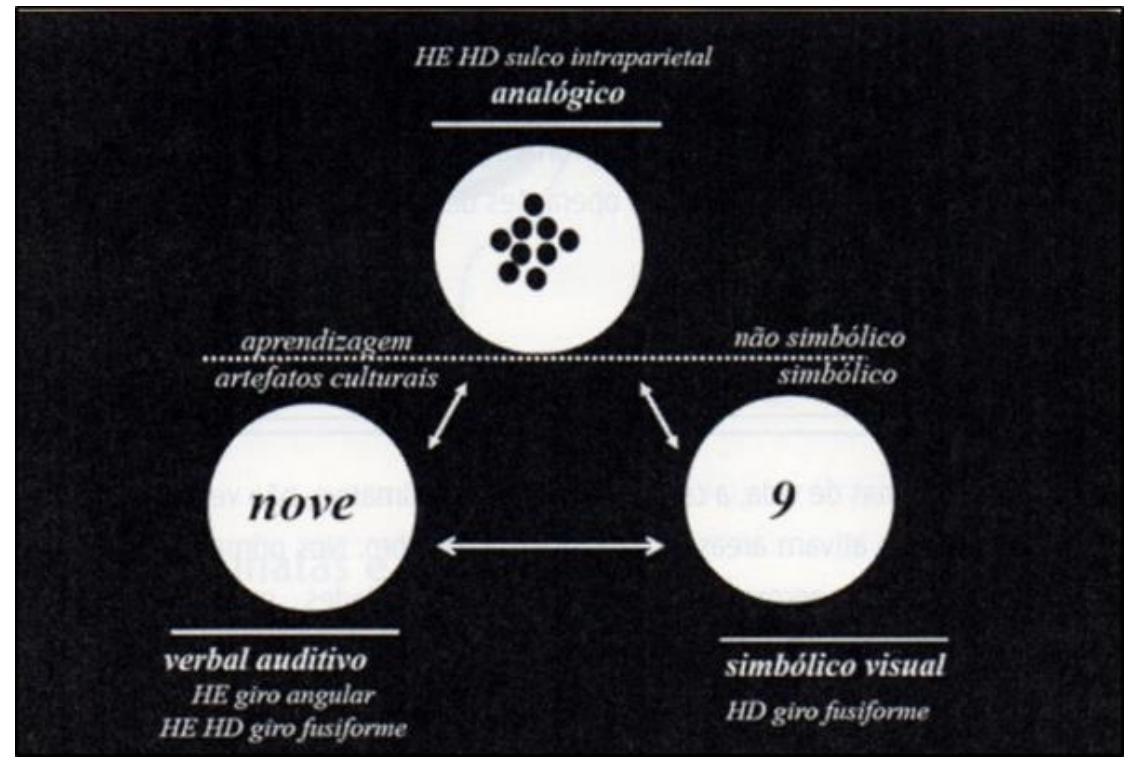

Fonte: MUSZKAT; RIZUTTI (2016, p. 133)

O Modelo de Código Triplo (Triple - Code Model), proposto por Dehaene e Cohen (1995) postula a existência de três diferentes códigos para representar números mentalmente: um código auditivo verbal, um código arábico visual e um código de magnitude analógico. A comunicação entre essas representações é realizada por meio de caminhos de tradução. $\mathrm{O}$ modelo especifica quais códigos internos são utilizados para quais operações numéricas, indicando que as mesmas representações de base são usadas em uma dada tarefa toda vez que for apresentado um formato de numeral. Nessa perspectiva, o código verbal é usado para a contagem e recuperação de fatos aritméticos, enquanto cálculos com muitos dígitos e julgamentos de paridade são mediados através do código arábico. A magnitude analógica representa a semântica numérica, a noção de quantidades e é empregada para comparação de magnitudes, estimações e cálculos de quantidade aproximada. No Modelo de Código Triplo há, portanto, o assentimento de um código verbal, ou seja, uma representação verbal entre as representações de base para a aritmética.

A partir desses elementos da Neurociência Cognitiva da Matemática que a pesquisa propõe a Musicalidade, entendida como "processo de estimulação" e não com vistas a resultados esteticamente ligados à arte, é desenvolvida por meio de vivências associadas aos elementos sonoros cuja organização é pautada nos teóricos: Edgar Willems (1968), Schafer (1991) e Edwin Gordon (2000), autores da área de educação musical que retratam sobre o 
ensino da música a partir de experiências de escuta, ritmos e corporeidade, associados com fundamentos teóricos da educação matemática (GOMES, 2014, 2015, 2016; GOMES; MANRIQUE, 2014, 2015).

Na constituição da Musicalidade destaca-se a escuta atenta (sensibilização sonora, audição como entrada sensorial para os circuitos neurocognitivos); a projeção espontânea e livre (expressão rítmica, sonora e corporal, organização psicomotora); as elaborações neurocognitivas (funções cognitivas específicas da matemática - transcodificação) em interação (integração com o meio - elaborações internas contextualizadas), especificamente às habilidades de Atenção Voluntária e Memória Operacional.

A pesquisa adota como referencial teórico da mediação docente a teoria da Modificabilidade Cognitiva Estrutural de Reuven Feuerstein (1997) que apresenta quatro critérios essenciais a todas as culturas: Intencionalidade e Reciprocidade, Significado e Transcendência. Os princípios norteadores contemplam que qualquer ser humano pode aprender, isto é, pode se modificar por meio da experiência mediada, independente de sua deficiência ou característica; que o mediador, imprescindivelmente humano, esteja posicionado entre estimulo e a resposta do aluno promovendo a dinâmica da Experiência de Aprendizagem Mediada. Fonseca (1995) que ressalta a plasticidade cerebral como consequência desta mediação caracterizada como multidisciplinar não apenas pela resolução de problemas mas pela interação provocada por meio dos critérios adotados, especialmente pela autonomia que é proporcionada ao sujeito mediado quando estimula processos cognitivos ao elaborar respostas a partir do seu conhecimento e experiência social e cultural.

\section{TDAH}

O Transtorno de Déficit de Atenção e Hiperatividade (TDAH) é um dos transtornos mais abrangentes do neurodesenvolvimento, tanto pela sua prevalência, como por seu impacto em esferas do desenvolvimento, e nas interações psicossociais. Em sua maioria, é associado a outros problemas, como dificuldades de aprendizagem, transtorno de humor, de conduta, de ansiedade e vários agravantes comportamentais e comorbidades que não apenas ampliam a dimensão do impacto como propõe desafios diagnósticos e sociais que devem ser abordados dentro de uma perspectiva interdisciplinar (MUSZKAT, 2012). 
Na quinta edição do Manual Diagnóstico e Estatístico de Transtornos Mentais (DSM V - TR, 2013) da Associação Psiquiátrica Americana (APA) o TDAH é classificado como Transtorno do Desenvolvimento envolvem a tríade sintomática de desatenção, hiperatividade e impulsividade, podendo ser classificado como: leve, moderado e grave de acordo com o grau de comprometimento que os sintomas causam na vida do indivíduo.

Segundo Muszkat (2012), o TDAH envolve principalmente disfunções de regiões préfrontais do cérebro, tornando-se fundamental a avaliação e desempenho em testes neuropsicológicos e medidas fisiológicas da atenção, controle inibitório, da organização e planejamento de tarefas, típicas das funções executivas. No TDAH são reconhecidas alterações de natureza neurobiológica, genética e neuroquímica, considerando que a expressão dos padrões herdados são também modulados pelo meio ambiente. Assim, o próprio ambiente é capaz de modificar a expressão de padrões endógenos, levando à grande heterogeneidade de apresentação clínica e diferentes influências de ambientes e estressores. Daí a variabilidade dos sintomas e a natureza multidimensional do TDAH.

São reconhecidas quatro regiões distintas do córtex frontal que se relacionam diretamente com os sintomas neurobiológicos do TDAH. A dificuldade de Atenção Seletiva relaciona-se com o processamento ineficiente das informações na região do córtex do giro cingular anterior, os sintomas de disfunção executiva se relacionam com a inabilidade de sustentar a atenção (Atenção Sustentada) e a dificuldade de resolução de problemas relacionase com a região dorsolateral do córtex pré-frontal, enquanto os sintomas de hiperatividade são ligados à área motora suplementar e ao córtex pré-motor.

A impulsividade relaciona-se com a modulação de áreas orbitofrontais, o que significa que o portador de TDAH tem grande dificuldade de se conter ou de coordenar movimentos, oportunizando a afirmação que a Musicalidade aqui descrita é capaz de além da estimulação cognitiva, atuar no controle emocional a ponto de motiva-los à se controlarem para participarem em harmonia com seus colegas.

\section{Metodologia}


Para o estudo experimental utilizou-se a metodologia qualitativa atingindo elementos preliminares da investigação a partir do aporte teórico. Os registros foram realizados por meio de observações sobre os fenômenos em alunos do segundo ano do ensino fundamental por uma professora regente de turma com 20 alunos, tendo um aluno com laudo médico de TDAH, com 8 anos de idade.

A professora participou de três estudos referente às áreas da Neurociência Cognitiva da Matemática; Mediação Docente e Musicalidade totalizando 60 horas. Para o planejamento e avaliação da atividade de Musicalidade foram confeccionados seis quadros indicativos e organizadores dos elementos constituintes das habilidades neurocognitivas para o ensino da matemática. Neste artigo será apresentado um deles.

A atividade de Musicalidade teve como objetivo a estimulação do cálculo mental, utilizando elementos do som, ritmo e corporeidade, visando o desenvolvimento do pensamento matemático abstrato. Os conteúdos curriculares abordados foram: metade, dobro e triplo.

Quadro 01 - Conceito de Número - Sistema de Numeração - Cálculo Mental - Proporcionalidade)

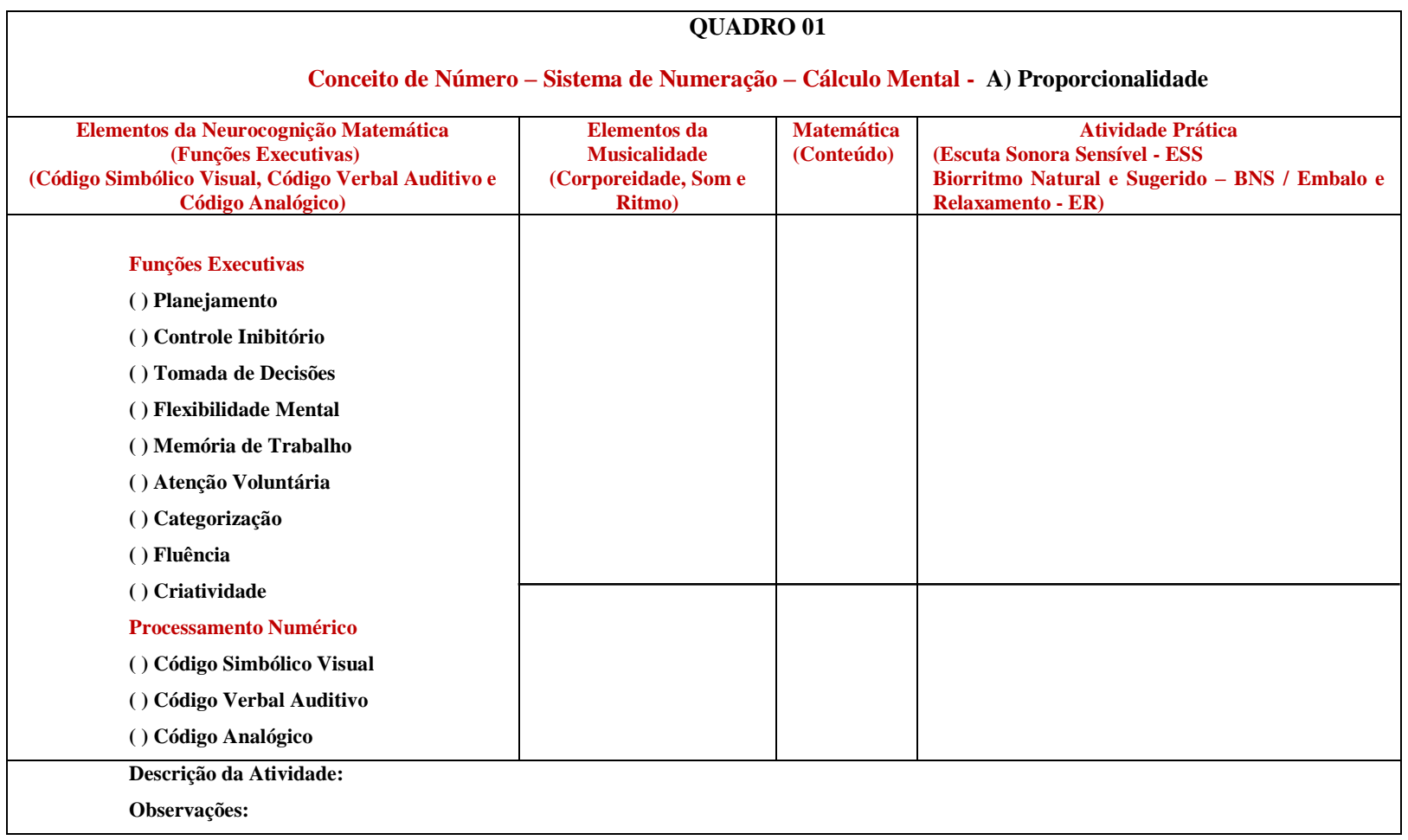

Fonte: elaborado pela autora (2017)

\section{Descrição da Atividade}


A professora criou a atividade utilizando a música "Passa a Bola". Esta música possui 16 pulsos e ao terminar sugere que a criança que esteja segurando a bola fale seu nome. Depois de realizar atividades referentes à marcação dos pulsos, canto e movimentos com todas as partes do corpo, as crianças contaram oralmente os pulsos utilizando a percussão corporal e cantando no ritmo estabelecido (métrica).

Propôs o desdobramento da atividade onde a criança que terminasse com a bola e falasse seu nome, deveria ouvir o nome da criança apontada pela professora e que correspondesse ao número da ordem crescente associado primeiro aluno de onde a música iniciou (entre 1 e 16).

A professora indicava tocando o instrumento musical a operação que deveria realizar: o cálculo da metade, dobro e triplo daquele numeral conforme o instrumento executado (metade - triangulo; dobro - tambor e triplo - caxixi).

Para realizar o cálculo o aluno escolheu a forma utilizando elementos concretos ou mentalmente. Estava disponibilizado na mesa ao lado do quadro: palitos de picolé, canudinhos de refrigerantes ou a caneta para o quadro branco da sala.

Após realizar o cálculo deveria entrar no círculo desenhado no chão ao centro da roda e apresentar o resultado por meio do número de palmas.

O resultado foi conferido na calculadora por outro aluno determinado pela professora, que não entrava mais na roda inicial para o canto da música e reinício da atividade. Desta forma todos os alunos participaram da atividade e conferiam os resultados dos colegas em suas calculadoras quando estavam no circulo central.

A professora relatou que um aluno percebeu que todas as vezes que repetia um numeral e o instrumento o resultado era o mesmo. Ela aproveitou o comentário para leva-los a reflexão sobre quantidades e numerais. Segundo o relato associou a adição com o dobro, a adição com três parcelas e multiplicação por 3 e divisão por 2 .

Relatou ainda que os alunos gostaram muito da atividade e pediram que ela repetisse no outro dia. Descreveu que alguns alunos não utilizaram o material concreto, outros sim, outros ainda utilizaram os dedos e alguns fizeram o cálculo mentalmente, entre eles o aluno com TDAH. Dos que realizaram o cálculo mental os resultados foram sempre abaixo de 20. Não houve nenhuma diferenciação da atividade para seu aluno com TDAH. Ele demonstrou 
controle inibitório e auto regulação desde o momento inicial da proposta da atividade até o final com todos os alunos, demonstrou alegria, entusiasmo e criatividade.

\section{Resultados e Análises}

Segundo o preenchimento do Quadro 01, observou-se que a professora utilizou os conhecimentos das funções executivas e Modelo Código Triplo para planejar sua atividade o que demonstra ter utilizado o critérios de Intencionalidade. $\mathrm{O}$ fato de todos os alunos terem participado da atividade com atenção, entusiasmo e criatividade demonstra que houve Reciprocidade. E Transcendência quando os alunos ao identificarem as representações manipularam as informações para realizar o cálculo mental. O que exigiu o conhecimento dos conceitos de metade, dobro e triplo.

Quanto à Musicalidade a professora utilizou a estrutura proposta de corporeidade, som e ritmo. A corporeidade na utilização do próprio corpo para passar a bola no ritmo estabelecido, visualizar os colegas e associar corpo com pulso. $\mathrm{O}$ som porque além da melodia que embala a atividade os timbres dos instrumentos musicais: triangulo, caxixi e tambor, representaram a operação matemática que deveriam realizar mentalmente ou com apoio concreto, e o ritmo porque os 16 pulsos significaram o limite inicial da quantidade que deveriam utilizar.

Quanto às funções executivas a professora identificou a presença de todas na atividade: a) Planejamento - o aluno teria que prestar atenção em quem iria começar a música para identificar a primeira parcela da operação a partir da contagem realizada na criança de onde a música começou; um segundo momento manipular a operação a partir da escuta do som do instrumento; e um terceiro momento utilizar um meio(material concreto ou calculo mental) para cumprir a tarefa; b) Controle Inibitório - a própria participação do aluno com TDAH apresentando auto regulação demonstra a presença dessa estimulação; c) Tomada de Decisões - para todos os passos da realização das atividades houveram escolhas; d) Flexibilidade Mental - associação quantidade numeral, tipo de operação entre as três propostas; e) Memória Operacional - em todos os momentos houveram informações que necessitavam de evocação para a resolução; f) sem Atenção Voluntária não se realiza cálculos matemáticos, é condição; g) Categorização e Fluência - presentes nos conjuntos de numerais, 
operações e tipos de instrumentos, utilização das palmas para a resposta; h) Criatividade - nos recursos utilizados para os registros do cálculo mental.

Quanto á estimulação dos códigos do processamento numérico, a professora não identificou a presença Código Simbólico Visual por não ter nenhum registro escrito da linguagem matemática; identificou o estimulo ao Código Verbal Auditivo quando ela fala o nome da criança que o aluno deverá identificar seu número correspondente da roda, e também ao representar em palmas a quantidade resultante, e a presença da estimulação do Código Analógico uma vez que o calculo mental manipula o sistema de numeração e suas relações para a resolução.

Além disso, a professora utilizou a calculadora para realizar a conferencia dos cálculos incentivando a utilização da linguagem matemática presente nas tecnologias. Registrou que todos os alunos possuem celular e que acharam muito positivo terem sido convocados a levarem nesta aula. Alguns alunos não haviam acessado a calculadora até a ocasião, o que também aprenderam com seus pares por terem modelos de aparelhos diferentes.

\section{Conclusão}

A Musicalidade é parte integrante de nosso repertório cultural e por si só é capaz de influenciar áreas do sistema límbico, responsáveis pela emoção. Com sensibilidade, interesse e criatividade o professor poderá utilizar elementos da musicalidade que indicam a possibilidade de tornar objetivos pedagógicos a estimulação de habilidades neurocognitivas típicas do pensamento matemático onde todos os alunos independente de suas características exercerão seus direitos de aprendentes (FERNANDEZ, 2001). A partir dessa associação é possível aos alunos, perceberem e vivenciarem as relações numéricas através da audição e movimentos da corporeidade. A sonoridade impulsiona a representação mental sendo possível identificar a estimulação de habilidades de atenção voluntária, controle inibitório e autoregulação para a construção do conhecimento do sistema de numeração e cálculo mental por meio da realização das tarefas propostas na atividade.

\section{REFERÊNCIAS BIBLIOGRÁFICAS}


CROSS, I.; MORLEY, I. Music and evolution: the nature of the evidence. University of Cambridge, 2006. Disponível em: https://www.academia.edu/487045/Music_and_evolution_the_nature_of_the_evidence > Acesso em 15 de Novembro de 2016.

DEHAENE, S., COHEN, L. Towards an anatomical and functional model of number processing. Mathematical Cogn. 1995.

FERNÁNDEZ, A. Os idiomas do Aprendente. Porto Alegre: Artmed, 2001.

FEUERSTEIN, R. Teoria de la Modificabilidad Cognitiva Estructural. In: Es modificable la Inteligencia? Madrid: Editora Bruno, 1997.

FONSECA V da. Educação Especial: Programa de Estimulação Precoce - Uma introdução as Ideias de Feuerstein. $2^{\text {a }}$ ed. Porto Alegre: Artes Médicas, 1995.

GOMES, H. C. A Educação matemática: jogos rítmicos para as funções executivas, uma proposta inclusiva para a deficiência intelectual. Anais VIII Colóquio Técnico - Científico do UniFOA , 2014.

Relações de Habilidades Matemáticas com a Musicalização (Ritmo - Som e Corporeidade) no processo de Estimulação da Inclusão. Anais do XXI Seminário Latinoamericano de Educación Musical - FLADEM/2015 - Rio de Janeiro, Brasil, 2015, p. 474 - 480. Disponível em: < http://www.fladembrasil.com.br/eventos-fladem.html > Acesso em 17 fev. 2016.

Educação Matemática Inclusiva: Modificabilidade Cognitiva Estrutural, Musicalidade e Mediação Docente. Enem - Encontro Nacional de Educação Matemática, São Paulo, 2016.

Música, Matemática e Inclusão: Uma Possibilidade De Intervenção Do Professor Mediador. In: Desafios da Educação Matemática Inclusiva: formação de Professores. (Org.) MANRIQUE, A.L.; MARANHÃO, M.C.S. de A.; G.E. MOREIRA. Vol. 1, Ed. Livraria Física, 2016. p 163-173.

GOMES, H. C.; MANRIQUE, A. L. Formação de Professores para Educação Inclusiva: A Musicalização na Alfabetização Matemática. Anais do II Congresso Nacional de Formação de Professores e XII Congresso Estadual Paulista sobre Formação de Educadores. Águas de Lindóia-SP. UNESP, 2014. p. 750-762.

Educação Matemática Inclusiva, Musicalização e Atenção Voluntária. Anais do Congresso Internacional de Educação e Inclusão. Campina Grande-PR. CPEI e UEPB, 2014.

A Musicalização (Ritmo - Som - Corporeidade) como Intervenção Neurocognitiva de Habilidades Matemáticas. Rev. RENCIMA - Universidade Cruzeiro do Sul, edição março/2015, v.6, n.1, p. 75-83, 2015.

GORDON, E. E. Teoria de Aprendizagem Musical: Competências, conteúdos e padrões. Lisboa: Fundação Calouste Gulbenkian, 2000. 
LE BOULCH, J. Educação Psicomotora: a psicocinética na idade escolar. Trad. de Jeni Wloff. Porto Alegre: Artmed, 1987.

LEZAK, M. D. The problem of assessing executive functions. International Journal of Psychology, 1982.

LURIA, A. R. Fundamentos da Neuropsicologia. Trad. Juarez Aranha Ricardo, Rio de Janeiro, Livros Técnicos e Científicos; São Paulo: Editora da Universidade de São Paulo, 1981.

MALLOY-DINIZ L.F.; PAULA J.J.; LOSCHIAVO-ALVARES F.Q. Exame das Funções Executivas. In: MALLOY-DINIZ L.F.; FUENTES D.; MATTOS P.; ABREU N. editores. Avaliação Neuropsicológica. Porto Alegre: Artmed. 2010, P. 94-113.

MUSZKAT M. TDAH e Interdisciplinaridade: Intervenção e Reabilitação. São Paulo: All Print Editora, 2012.

PEDERIVA, P.; TUNES, E. Musicalidade, fala expressão das emoções. In: Anais do SIMCAM4 IV Simpósio de Cognição e Artes Musicais, SIMCAM4. P. 1-5. 2008.

SCHAFER, M. O Ouvido Pensante. Trad. de Marisa Fonterrada. São Paulo: Ed. Unesp, 1991.

WILLEMS, E. As Bases Psicológicas da Educação Musical. Suíça. Trad. Ed. Pró Musica, Bienne, 1968. 